\title{
Healthcare and SDGs Governance in Light of the Sustainability Helix Model: Evidence from the African Continent
}

\author{
Marialuisa Saviano ${ }^{1, *}$, Fabiana Sciarelli ${ }^{2}$, Azzurra Rinaldi ${ }^{3}$ and Georcelin G. Alowanou ${ }^{4}$ \\ 1 Department of Pharmacy, University of Salerno, 132, 84084 Fisciano, Italy \\ 2 Department of Literary, Linguistic and Comparative Studies, University of Naples "L'Orientale", \\ 80138 Naples, Italy; fsciarelli@unior.it \\ 3 Department of Law and Economics, University of Rome Unitelma Sapienza, 295, 00161 Rome, Italy; \\ azzurra.rinaldi@unitelmasapienza.it \\ 4 Faculty of Agronomic Sciences, University of Abomey-Calavi, 01 BP 526 Benin, Africa; \\ galowanou@gmail.com \\ * Correspondence: msaviano@unisa.it
}

Received: 31 December 2018; Accepted: 20 February 2019; Published: 25 February 2019

\begin{abstract}
This work is based on a view of healthcare as a fundamental Sustainable Development Goal (SDG) to share globally to be effective at local level. On this basis, the paper analyzes the health programs in less-favored areas with the aim of understanding why the United Nations SDGs are so difficult to reach in some countries. A brief review of the main literature and research on the health governance systems in three countries of the African continent have been conducted to this aim. The results are interpreted through the sustainability helix model (SHM). Key roles and conditions of effectiveness of the health sustainable development governance approach in the investigated countries are discussed. The main findings reveal that the analyzed governance systems lack implementation plans. By discussing the observed problem in the light of the sustainability helix model, fundamental elements of a health sustainable development helix model have been identified in less favored countries where key actors and roles are identified. The study highlights, in particular, the relevance of 'interface' roles played by non-governmental actors (NGA) and international actors (IA) in the health governance system of less-favored countries. These actors and roles allow connections between the global and the local levels of action favoring interaction among actors institutionally devoted to governing development.
\end{abstract}

Keywords: health; programs; sustainable development; sustainable development goals; sustainability helix model

\section{Introduction}

Sustainability today is a global goal. Achieving social, economic and environmental sustainability is no longer a target reserved for rich countries, but it must be a goal for every countries in the world, to be shared globally at the same time considering the local conditions of development. It has been realized that even by raising a wall between one country and another, there are elements that go beyond any boundaries and which influence, involve and contaminate all the territories. Therefore, sustainability can no longer be a country goal, it can not be enclosed in borders and must be implemented in a collective way. This view, however, appears to contradict the national and international logics that have guided the cooperation system to date. Today Ubuntu-Umuntu ngumuntu ngabantu, "I am what I am, by virtue of what we all are"-is no longer just a possibility but has become a certainty to be respected worldwide. The logic is that everyone must work all at 
the global sustainable development agenda, in particular for the environment and, therefore, global health, to see effects at a local level.

In this context, it is extremely important to understand that the advanced (developed) countries must not strive for global sustainability by following a feeling of compassion for weak countries, nor for fear of threats from health-threatening countries, but in a logic of global necessity. A population today can no longer grow in solitude because,: from an economic point of view, it needs other countries, for example, in the context of a commercial globalization; from an environmental point of view, because of water, air and even land are public goods that can not be confined and therefore, for example, the pollution of groundwater in a country necessarily involves in the short term the neighboring countries and in the long term even far ones; and from a social point of view, because, for example, if global acquired immuno-deficiency syndrome (AIDS) is not defeated, it can not be truly defeated at the local level.

Therefore, assuming that sustainable development requires planned action at global level and to be coherently implemented at local level, the focus is on creating sustainable human development in weak countries adopting the global perspective of the United Nations and wondering why the SDGs are so difficult to reach in some countries.

On the basis of this premise, this work develops a reflection on the effectiveness of healthcare programs in weak countries. Framing the problem as strictly linked to development, the study has been conducted exploring the contribution of the sustainable development perspective and embracing the United Nations' global and holistic view. In particular, the study adopts the Sustainable Development Goals (SDGs) framework [1] as a useful reference for framing healthcare as a development goal, and discusses as a development problem the following research question: "Why do healthcare programs not lead to the achievement of the health SDG in weak areas?"

"Good Health and Well-Being" is the third SDG and aims to ensure a healthy life and promote well-being for all ages, an essential objective for sustainable, balanced and lasting human development. Since the improvement in the health sector is still very far from reaching an acceptable life expectancy in all countries, the third SDG is divided into 13 objectives, which contain the major health concerns of our planet such as maternal and child mortality or deaths from AIDS. As emerges from the sub-objectives, their achievement, which is necessary for sustainable global development, cannot be separated from the systematization of a strategic management approach to healthcare "in particular developing countries" [2].

Framed as a development problem, the main research question leads to more specific objectives regarding (1) what the dominant theoretical perspectives are and what the contribution of managerial studies could be; (2) how new models can help to frame theoretically and practically the approach to health development in weak countries; and (3) what evidence emerges from weak countries' contexts.

Accordingly, first, a very brief review of the main literature on the topic is conducted to identify possible gaps and limitations; then, novel theoretical and practical models to approach health development in weak countries are searched by exploring the contribution of different theoretical perspectives; subsequently, an empirical investigation is conducted by identifying three very different countries in the African continent that offer evidence of the main conclusions of the theoretical stage of the study; finally, the overall results of the study are discussed with the sustainability helix model as theoretical support developed within the research stream of the viable systems approach (vSa) [3-7].

The work is organized as follows: after this introduction that outlines the main research question as well as more specific objectives (Section 1), are illustrated the materials and methods used (Section 2); then, the results of the overview of the main literature and of the empirical study conducted in the selected countries are shown (Section 3); subsequently, there is the discussion about the results of the study through the lens of the sustainability helix model providing indications for possible lines of action and the main elements of a sustainable health development system model (Section 4); finally, some concluding remarks and future directions for research are outlined (Section 5). 


\section{Materials and Methods}

Methodology

The primary research question, which is "Why do healthcare programs not lead to the achievement of the health SDG in weak areas?", immediately directs attention to a mixed research method that includes qualitative and quantitative analysis of secondary data, and on field analysis, which is carried out by conducting interviews with privileged witnesses of public institutions, intergovernmental institutions and non-governmental actors (NGAs).

Following the three research objectives, a very brief review of the main literature on development economics has been conducted, which is traditionally devoted to identifying the development factors in emerging countries, to have an overview of the dominant approaches and possible gap (objective 1). This review reveals a main limitation in ignoring the peculiarities of the local conditions of countries 'waiting for development'; hence a divide between the global view and the local action.

Searching for novel models capable of overcoming this limitation (objective 2), there was a shift in focus from the theoretical context of development economics to that of managerial studies, where you can find useful contributions to the governance of business and social organizations from the systems thinking stream [8]. Continuing the research, to reach the second objective the actors involved in the national health system have been analyzed with the aim of achieving the SDGs: in addition to public actors, the international community and the NGAs are considered.

More specifically, the reference is to recent advancements in the managerial studies on sustainability that provide insights and reference models of governance for sustainability suggesting the adoption of systems approaches capable of integrating relevant actors and roles in a unitary framework and favoring the share of views and goals at global and local level [9]. On the basis of these materials, an appropriate interpretative tool useful to identify key problems and possible solutions trajectories in the governance of health has been sought by adopting a systems view. Among the numerous contributions offered in the field of managerial studies, the focus is on streams that provide contributions to governance and management approaches which adopt a system thinking perspective, which is considered fundamental for having a holistic view of the investigated problems.

At the same time, in order to combine the search of theoretical models with empirical evidence from weak countries (objective 3), the focus is on the African continent, identifying three very different countries supporting the main conclusions of the theoretical stage of the study.

We have chosen three countries with different Human Development Index (HDI)-South Africa $0.699,113$ th country in the world, Ethiopia 0.463 in 173th place and Bénin 0.515 in 163th place-with different characteristics (South Africa second country of Africa for Gross Domestic Product (GDP), Ethiopia second most populous country, Bénin, a small village with a small outlet to the sea), in three geographical areas of the African continent (South, Central East, North-West) and with three types of planned healthcare development distant from each other. On the whole, these three nations are considered quite representative of the African continent.

To conduct this phase of the research, the government officials have been contacted and, together with the international actors involved, gave us access to their strategic plans for the last 30 years. We analyzed and commented on some of the main ones: South African health development plans, like the National Development Plan (NDP) 2013-2030, and the Medium-Term Strategic Framework (MTSF) 2014-2019; Ethiopian health development plans, like the Health Sector Development Program (HSDP) IV (2011-2015), Health Extension Programme (HEP) and the Growth and Transformation Plan (GTP I) 2010/11-2014/15 and GTP II 2015/2016-2019/2020; Beninian health development plans, like the National Health Development Plan (NHDP), 2009-2018, La Stratégie de Croissance pour la Réduction de la Pauvreté (SCRP 2011-2016), Programme d'Actions Prioritaires (PAP), e Multi-Annual Strategic Plan 2014-2017 (MASP).

Numerous interviews have been carried out through United Nations (UN), United Nations Development Programme (UNDP) and World Bank (WB) representatives. Thanks to this phase of 
the research, there has been access to a large number of UN, UNDP and WB databases, including the internal reports and statistics, the internal queries, papers etc.

Finally, all the data from World Bank, UNDP, national governments, etc. have been analyzed and processed (these data are available online and in the databases above) regarding, among the other things, the use of IT tools. In addition, there have been conducted about 100 interviews with a random sample of ordinary citizens of the three countries.

This empirical stage of the study was conducted collecting both secondary data, which provided a wide programmatic documentation dedicated to the development of the investigated countries, and field data, which revealed several anomalies in the local health development programs drawing a very chaotic picture, similar to Chinese boxes, and demonstrating a clear lack of systems action to achieve the health SDG in these weak countries. In this final stage of the research, both the interpretation of the observed problems and the search for possible solutions are supported by the use of the sustainability helix model developed within the research stream of the vSa [3-7] integrating the triple helix model by Etkowitz [10] and the triple bottom line framework by Elkington [11]. The use of the model allows us to outline a systems model for the achievement of the third SDG, Good Health and Well Being: the sustainable health development system model.

\section{Results}

\subsection{Overview of the Literature on Development (Objective 1)}

The existing literature on development has long focused on identifying the factors that are able to initiate and support a development process in emerging countries. In most cases, what had already happened in the advanced countries was modeled $[12,13])$. This setting, which has been dominant for a long time, showed, however, little validity both from a practical and a theoretical point of view. One of its main limitations lies in ignoring the peculiarities of the analyzed countries. At the same time, it tends to underestimate the negative impact that the coordination of economic policies may have exerted on the paths of growth and emancipation from the condition of poverty [14]. Trying to fill these limits and provide useful tools to policy makers of emerging countries, who intend to embark on an endogenous development path, new analytical approaches that propose an innovative and integrated way of thinking about development are emerging. For example, some authors propose a review of economic instruments capable of understanding the development of countries awaiting development [15]. In this context, a great innovation can be made by drawing at the same time from economics and management in order to build a synergy of tools that can be more effective. In this new approach, the focus is on the characteristics of the emerging country. In this way, it is possible to imagine a development path that is tailor-made, based on the involvement of local actors and truly sustainable [16-20]. This literature supported the design of the method used for this paper. Finally, in the economic literature dealing with the development of emerging countries, an important role has traditionally been played by the analysis of the impact of the health sector on variables linked to development [21-23]. Therefore, it is possible to state that the existing literature provides a broad framework within which this work is inserted.

\subsection{Novel Interpretative Models: The Viable Systems Approach (vSa) Sustainability Helix Model (Objective 2)}

It is now widely agreed that, to realize true sustainable development in any country it is necessary to achieve sustainability at economic, social and environmental level. The most common representation of such necessity is the well-known triple bottom line (TBL) elaborated by Elkington in 1997 [11]. There are indeed further ways to represent the multiple dimensions of sustainability; as, for example, the "three pillars" one [2]. These kinds of representation, however, are less useful to highlight the necessity to achieve sustainability as the outcome of effective interaction among the three dimensions: environmental, social and economic. 
Hence, the three circles model by Elkington makes clear the need of such interaction. In the adoption of the model, a problem remained, however, regarding 'how' interaction among the three dimensions is effectively realized. This aspect has been analyzed by the vSa stream that provides an interpretive framework useful to understand the interaction problem.

Recognizing the necessity to trigger a systemic interaction among the three spheres of sustainability, the vSa suggests identifying the key to such systemic dynamic in the context of sustainability by using the general framework of systems thinking [7,24]. According to Barile et al. [25], as shown in Figure 1, the interaction space within the TBL representation suggests a typical 'helix' functioning. This evidence directed the authors to explore the possible contribution of the triple helix model (THM), which represents a similar dynamic [26].

The THM was originally developed by Etzkowitz [10], and Leydesdorff and Etzkowitz [26], to analyze innovation processes as outcomes of effective interaction among three key institutional agents: universities, industry, and government [27]. According to the model, virtuous collaborative relationships between the three institutional actors are to be established and in this case university plays a central role. A key assumption of the model is that, when it is necessary to develop the expected interaction dynamic, temporary 'replacement' of roles among the three actors should be performed realizing the so-called 'hybridization' process: basically, each of the three actors is expected to play one other's role if useful or necessary to the whole functioning.

Hence, by integrating the THM into the TBL framework, as proposed in Figure 1, it is possible to give account for the systemic functioning of the TBL, that is, more generally, the interaction between the three dimensions of sustainability $[25,28-30]$. At the same time, society and natural environment would be also included in the THM without adding new blades, as suggested in other proposal that takes a different view [31].

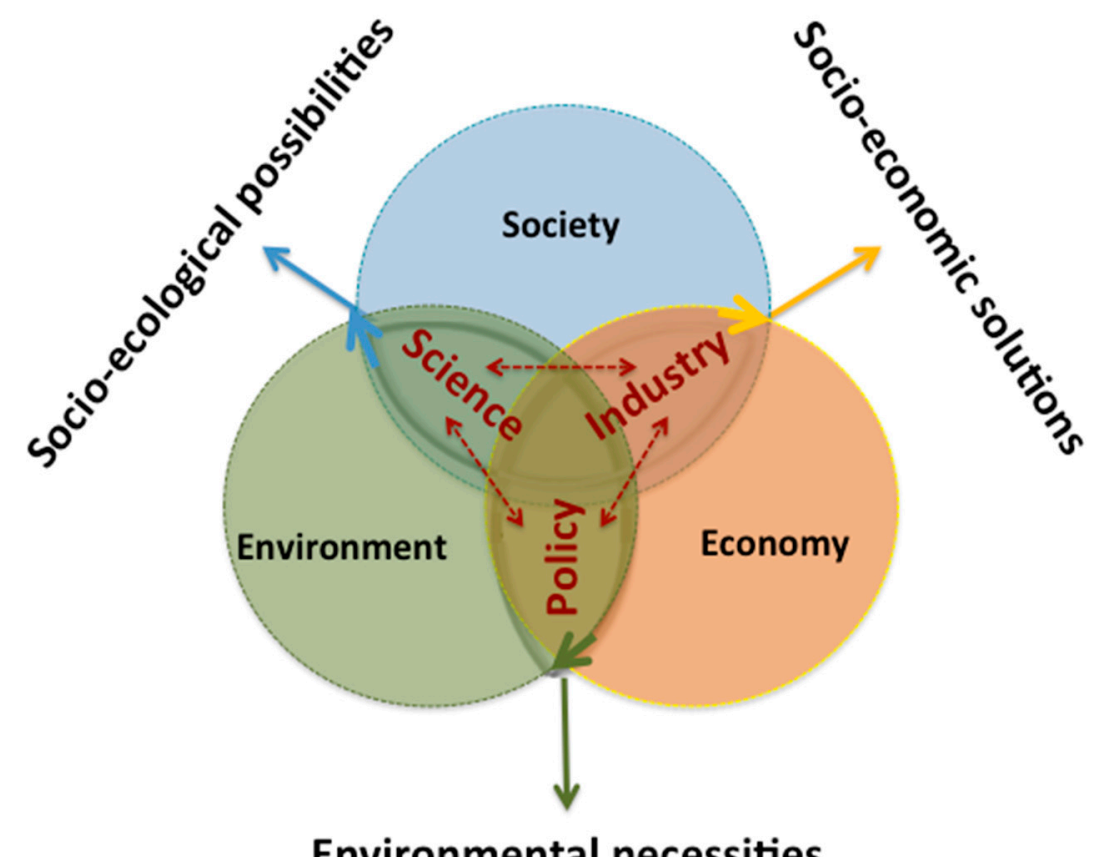

Figure 1. The viable systems approach (VSA) sustainability helix model (authors' elaboration on [32]).

In the integrated model, the 'helix' is viewed as the institutional mechanism that explains interaction between the environmental, social and economic dimensions of sustainability, as the outcome of a coordinated and coherent action of the three key players represented by government, university and industry. It goes without saying that the reference is not to defined actors or institutions but to categories of actors, or even better and more substantially, to roles that can be played by any actor, who is officially authorized or even informally recognized as appropriate to that role. 
As illustrated in Figure 1, the helix movement is represented by the dynamic of interaction between the three key actors of sustainable development: policy, science and industry. Their roles are the following [33]:

1. Policy interprets the environmental necessities, that are the constraints to comply with when using the environmental resources;

2. Science defines the socio-ecological possibilities, that is what can be done thanks to the progress of knowledge complying with the environmental necessities;

3. Industry develops the socio-economic solutions, that are the feasible possibilities selected among the possible ones.

The logic of the model is that each actor can play any role that is necessary for the achievement of the development target. This interchange of roles represents the THM 'hybridization' process. Hence, the core of the model is that actors should play their roles by realizing a virtuous interaction (helix functioning) synergistically pursuing shared goals. On the basis of these hybridization' processes, the model introduces possible 'interface' roles that are potentially relevant when institutional agents do not play or are not effective in playing their roles. These interface organizations can act both by replacing other actors and connecting them into a virtuous whole interaction dynamic.

As mentioned, the use of this model in the research gives us the chance to analyze the governance problems identified in the investigated countries and to discuss a possible solution paths particularly focusing on the roles played by the development actors.

\subsection{Health Programs in Less-Favored Areas: South Africa, Ethiopia and Benin (Objective 3)}

The problem of the health sector and the achievement of the third SDG varies a lot with respect to the territory that is taken into consideration. The World Bank data show an imbalance in the indexes that is absolutely responsive to the imbalance in the management of healthcare in the world.

Understanding why this happens and what could be done to improve the situation is the main motivation that prompted us to conduct the research, first and then write this article. The main question can then be translated into this more specific one: why, despite all the efforts of the international community and individual governments for the improvement of collective well-being, are there still disparities of more than 30 years of life expectancy between one country and another? What is missing in weak areas for development?

The difficulty of precisely defining the characteristics of a marginal area derives from the variety and diversity of the problems affecting this type of area, problems that are not only of an agricultural nature, but also of a socio-economic nature. As stated by Pender and Hazell [34], these areas are "less favored by nature or man".

Regardless of the causes, the population that was born and resides in these disadvantaged areas is mostly condemned to a state of poverty. The weak areas of the world are thus considered those that have a low or very low 'Human Development Index' but also some areas that have medium (but unbalanced) human development can be absolutely included in the definition of less favored areas, especially for health [35-38].

To begin understanding what happens and what is missing, the African continent, situated at very low levels of human development, was chosen. Therefore, three countries on the continent that represent different areas, types of development and growth (especially in the health sector) have been chosen. For these reasons, we selected South Africa (medium human development), which from an economic point of view is the second country in Africa, but that is destroyed by the phenomenon of AIDS (an SDG sub-objective); Ethiopia (low human development), which is a country in change today, whose development in the last 20 years has grown slowly but steadily and that has invested in healthcare; and Benin (low human development), which is a small country located to the West, which is still very dependent on the international community and is currently undergoing a significant health system reform. 
Through the study of these countries a nodal point of the problem of healthcare has emerged: the lack of implementation of the plans. As you will see later, in fact, it emerges that all three countries envisage impressive and serious strategic plans for the achievement of the third SDG and its sub-objectives, but that none of the three envisages equally serious and detailed implementation plans. As will be highlighted, the real implementation of the plans, even if parceled out, is in the hands of Non-Governmental Actors [9], i.e., NGOs, religious institutions, civil society and the third sector in general.

\subsubsection{Health Strategy of South Africa}

The South African Republic is located at the southern tip of the African continent, home to 55.91 million inhabitants (2016) in an area of 1,221,000 $\mathrm{km}^{2}$ and consists of nine autonomous provinces. The current constitution was enacted on 10 December 1996. The President, who is also Head of Government, and therefore has very broad powers, is elected by the people and exercises executive power directly.

In 2017, GDP was $\$ 294.8$ billion (about 4 times that of Ethiopia). The GNP per capita PPP amounts, in the same year, to $11.923 \$$. The country is at 113th place for human development (HDI 0.699). The economy of South Africa is the second richest on the continent, after Nigeria. The country accounts for $24 \%$ of Africa's Gross Domestic Product (Purchasing Power Parity - PPP), and is classified by the World Bank as a medium-high income economy.

In South Africa, the health system and social security are very well developed and have been highly integrated for a long time, both in the public and private sectors, guaranteeing benefits or subsidies to the unemployed, the civilian and military disabled, the elderly and people with chronic diseases. Medical assistance is free for children under six and for pregnant women. Unfortunately, all this is not yet enough to guarantee a health system similar to that of a Western states. For this reason, the National Development Plan (NDP) and the Medium-Term Strategic Framework (MTSF) pay great attention to reform of the national health system.

The NDP, which is the long-term National Development Plan (2013-2030) aims to reach, by 2030 [39], an average life expectancy of the population of 70, a new generation without AIDS and an infant mortality rate of less than 20 each 1000 births (rising to 30 for children under five). Chapter 10 of the NDP explains all the objectives related to the national health system, the 26 indicators and actions for the realization of the macro-objectives that constitute the vision. The plan also clarifies that there are no quick and effective solutions that enable the set of nine objectives to be achieved simultaneously. The plan itself, therefore, defines nine priority activities, that in turn will be divided into programs and then into actions that are necessary to achieve a more efficient health system.

The plan highlights the need for greater inter-sectorial and inter-ministerial collaboration, which is fundamental for the development of the health system throughout the national territory and for the achievement of the third SDG. The fact that public and private health structures and traditional healers still coexist is an obstacle to ensuring an effective national health system. However, the plan states that traditional know-how cannot be underestimated. Finally, the document considers it essential to promote a national health insurance system, to reduce the prices of private medical assistance, and to improve the professional and management skills of health facilities and infrastructures.

The National Institutes of Health (NIH) estimates that public health spending will increase from R100 to R110 billion in a first phase, to reach R255 billion in real terms (R574 billion in nominal terms) in 2025, with an increase of two percentage points on GDP. Health care coverage should be split between multiple financial sources, such as taxes, National Health Insurance (NHI), private insurance, out-of-pocket payments, community funding, and donations. The NHI funding model, that the plan provides, should have an effect on three fundamental factors: the universal provision of quality health care, social solidarity through cross-subsidies and equity in access through free health care [40].

In the Medium-Term Strategic Framework (MFTS 2014-2019), it is stated that the average life expectancy of South Africans has increased thanks to advances in public health services (World Bank 
Data 2018) [41]; medical visits per year rose from $€ 67$ million in 1998 to $€ 128$ million in March 2013. Today, the same amount of resources is paid to each of the two components of the South African health system (public and private), even if over $80 \%$ of the population chooses mainly public facilities.

In the period from 2014 to 2019, the document identifies some focal points of the reform process, such as improving the quality of health care and reducing waiting times. It also states that this should be supported by the institution of health compliance standards and the patient card subscription. The plan also aims to strengthen and reorganize the basic health care system, including the Outreach teams and school health services. District health services must be expanded by involving the NHI. It is expected that the availability of contraceptives and information on AIDS will continuously increase, to eliminate sexually transmitted diseases and to reduce unwanted and untimely pregnancies, similarly to what has been promoted by the African Union in the Campaign for the Accelerated Reduction of Maternal Mortality in Africa (CARMMA).

The actions that the MTSF intends to achieve by 2019 concern health infrastructures, staff training and immunization. The objectives for 2019 are: the increase in life expectancy at birth at 63 (in 2016 it was 60 years); the reduction in the under-five infant mortality rate to 23 children per 1,000 live births (in 2016 equal to 39); the reduction of the infant mortality rate to 18 out of 1000 live births; and the reduction of the maternal mortality rate to 100 per 100,000 births (in 2015 equal to 138). The estimated cost to reach the medium-term health plan is R502, 303 million, which represents $13 \%$ of the total Medium-Term Expenditure Framework (MTEF) [42]. Analyzing the plans, although in the MTEF the approach is more oriented towards specific objectives, both appear as strategic plans not linked to specific implementation plans.

\subsubsection{Health Strategy of Ethiopia}

Ethiopia is a country located in the Horn of Africa. With its 106.5 million inhabitants in 2018, it is the most populous country in the world that is landlocked, as well as the second most populous nation of the African continent after Nigeria. It is located in the central-eastern part of Africa, covering an area of $1,104,300 \mathrm{~km}^{2}$, its GDP was $\$ 72.37$ billion and the per capita GDP $\$ 706.76$.

Ethiopia today has 9 semi-autonomous administrative regions that have the power to collect taxes and spend them independently. In March 2018 there were the last national elections and in October 2018, for the first time in the history of the country, a female president was elected. Under this government, the Ethiopians enjoy greater political participation and greater freedom of political debate than any other moment in their history.

In recent years there has been considerable progress in health care, such as the expansion and construction of health facilities and improvement of the quality of health services. From 2004 to the 2009 financial crisis, Ethiopia was one of the fastest growing economies in the world. Despite this growth, GDP per capita is still very low, because civil wars and recurrent drought have made Ethiopia one of the poorest countries in the world. In 2017, Ethiopia was at 173th place for human development.

The Health Financing System [43] within the Health Sector Development Program (HSDP) IV (2011-2015) [44] provides reference scenarios for achieving the international community development goals (MDG and SDG). Currently in Ethiopia, there are three main types of sources of funding for the health sector: revenue from public administrations, development partners and families. The funds from these sources flow to structures through different paths. The HSDP IV Financing Sources and Funds Flow [44] outlines the flow of funds from different sources.

What is not reflected in this figure is the government's plan to provide financial protection through a combination of two health insurance schemes: the Social Health Insurance Scheme (SHI) and the Community Health Insurance Scheme (CBHI). Even in the case of Ethiopia, it is clear how many different actors intervene in the health system.

The Health Extension Program (HEP 2016) is an innovative program for the provision of health services aimed at universal coverage of primary health care. The program is based on the expansion of physical health infrastructures and health extension workers (HEW), structures that provide preventive 
and therapeutic health services based on the rural community. The priority areas of the Ethiopian health sector development program, as envisaged by the MDGs before and by the SDGs, include maternal and neonatal care, children's health and the overcoming of the spread of the most transmissible diseases, such as AIDS, tuberculosis and malaria.

The essential elements of Ethiopian health policy in recent years have been: democratization and decentralization of the health system, development of prevention, guarantee of access to health care for all segments of the population and promotion of the private sector and NGOs in the health sector.

The quality of the health service applies a triple approach to improve the quality of health services: increase the flow of resources for the health sector, improve the efficiency of the use of resources and ensure the sustainability of funding to improve coverage and quality health services; involve the community in planning, implementation, monitoring and evaluation of health interventions; and affirm the role of the private sector as a provider of health services.

According to the plan, to provide a quality health service private health workers must also be strengthened, motivated, monitored and regulated in order to best meet the needs of citizens. Significant results have been achieved in the health sector during the Growth and Transformation Plan 2011-2016 (GTP I): 38,000 health workers have been distributed throughout the country. As a result, coverage of primary health care service increased to $98 \%$ in $2014 / 15$. Ethiopia has proved exemplary in meeting the international targets set in the health sector before the date envisaged.

With the GTP II (2016-2020), the progress made so far must be further improved [45]. It is necessary to expand healthcare infrastructure, develop human resources, improve health institutions, leadership skills and the work system, strengthen pharmaceutical supply and logistics management and engage communities. Finally, the development of a sustainable financing system is expected to be based on the implementation of the health insurance policy already envisaged by the government. Although health insurance was approved and established, the social insurance system was not, in fact, made during the GTP I. Therefore, GTP II pays particular attention to the implementation of the social health insurance system and to the improvement of quality health services.

Even in the case of the numerous Ethiopian strategic plans, which have produced greater real results, all the strategic elements, such as vision, mission, objectives, actors involved, are clearly visible, while the operational elements and above all the definition of the implementation are less clear and defined. Also in Ethiopia, there is a system of strategic planes that cross and overlap, dispersing the traceability of the result.

\subsubsection{Health Strategy of Benin}

Bénin is a small presidential republic located in the central-western part of the African continent, between Togo and Nigeria, with a small outlet to the sea.

Since the end of the Marxist-Leninist regime in 1989, Bénin has had a stable and democratic government. The head of government and state is the President, elected in presidential elections held every five years. The president then appoints a council of ministers.

The Republic of Bénin has 10.87 million inhabitants, covers an area of $114.763 \mathrm{~km}^{2}$ and its GDP is $\$ 9.274$ billion US dollars (2017). Since 2006, Bénin's GDP has been steadily growing. GDP per capita also recorded growth in the last few years, reaching $\$ 829.80$ in 2017. In Bénin there are about 40 different ethnic groups, the largest being the Fon which represents about $40 \%$ of the population. Each of them has its own language, although the official language remains French.

Poverty remains a widespread problem in Benin, with national poverty rates of $40.1 \%$ in 2015 . In Benin, life expectancy at birth in 2017 is 61.2 years (in 2005 it was 57.4) (Table 1), the GNP per capita PPP amounts to $\$ 20.61$ and the average school attendance is equal to 3.6 years (compared to an expectation of 12.6 years). For these reasons, the country has a Low Human Development with a rank equal to 163.

After 1999, Bénin began the development and implementation of poverty reduction strategies. After the Stratégie de Réduction de la Pauvreté Intérimaire (SRPI), completed in 2000, the Strategies 
de Réduction de la Pauvreté (SRP 1) 2003-2005 served as a strategic element of accreditation and dialogue towards international technical and economic partners. The National Health Development Plan (NHDP) [46], together with the long-term Stratégie de Croissance plan for the Pauvreté 2009-2018 reform (SCRP), reflects the desire of the Ministry of Health and technical and financial partners to provide rapid and effective answers to population health problems. The plan's vision is summarized by the following statement: "In 2025 Benin has (will have) an effective health system based on public and private, individual and collective initiatives to ensure the continuous supply and availability of quality, equitable and accessible care to all segments of the population, founded on the values of solidarity and risk-sharing in response to the health needs of Benin's people" [46]. To achieve this vision, the NHDP is divided into five priority areas (1. Preventing and combating major diseases and improving the quality of care; 2 . Developing human resources; 3. Strengthening partnership in the sector, promoting medical ethics and responsibility; 4. Financing mechanism for the sector; 5. Strengthening the management of the sector), 13 programs and 39 sub-programs, whose efficient implementation could enable the sector to meet the challenges and achieve the goals.

Table 1. Life Expectancy at birth.

\begin{tabular}{cccccc}
\hline \multicolumn{5}{c}{ Life Expectancy at Birth, Total (Years) } \\
\hline Country & $\mathbf{2 0 1 0}$ & $\mathbf{2 0 1 3}$ & $\mathbf{2 0 1 4}$ & $\mathbf{2 0 1 5}$ & $\mathbf{2 0 1 6}$ \\
\hline South Africa & 54 & 57 & 61 & 62 & 63 \\
Ethiopia & 61 & 64 & 64.5 & 65 & 65 \\
Bénin & 59 & 59 & 60.4 & 60.6 & 61 \\
\hline
\end{tabular}

Source: Authors' elaboration on World Bank Data [47].

The objectives of the plan, in line with the SDGs, tend essentially to: reduce poverty-related illnesses; improve the health of the mother and child; identify and control the main diseases; strengthen the institutional capacity of the health sector, in order to make it more appropriate for the implementation of the necessary reforms and strategic plans. To make the NHDP more operational, three-year development plans (3YDP) are foreseen and implemented, which must provide a precise and detailed framework for the implementation and monitoring of the 10-year plan. Therefore, at the departmental level, such as the health department, the technical coordination of the NHDP works with the implementation mechanisms of the three-year departmental plans.

The total budget for the NHDP is CFA 2.255 billion. The sources that contribute to the financing of the global plan are the governments, the community and the technical and financial partners. Also here, as for the previously analyzed countries, can be noticed the definition of cascading strategic plans. In fact, short, medium and long-term strategic plans are highlighted.

Also here, as for the previously analyzed countries, strategic trickle-down plans are highlighted. In fact, there are some long-term strategic plans in the medium and short term. Although the three-year plans are considered in the writing of the operational plans, a careful analysis shows that they are also strategic plans.

\section{Discussion}

As can be seen from the data (Table 2), many years of international cooperation have failed to significantly reduce the existing gaps. The health sector of the world has grown, both from a quantitative (infrastructural) and from a qualitative point of view, in every territory, with different speeds. The problem that emerges from the analyzed data is not the trend of the healthcare development indexes (a trend that is now steadily positive), but rather the gap between countries, which does not seem to improve. 
Table 2. Health indicators.

\begin{tabular}{cccc}
\hline & \multicolumn{3}{c}{ Health Indicators 2015/2016 } \\
\hline Country & $\begin{array}{c}\text { Health Exp. } \\
\text { PP (\$)—-2015 }\end{array}$ & $\begin{array}{c}\text { Health Exp. } \\
\text { (\% GDP)—2015 }\end{array}$ & $\begin{array}{c}\text { Life Expect. } \\
\text { at birth-2016 }\end{array}$ \\
\hline South Africa & 470.80 & 8.2 & 63 \\
Ethiopia & 24.28 & 4.05 & 65 \\
Bénin & 31.29 & 3.99 & 61 \\
\hline Organisation for Economic & & & \\
Co-operation and Development & & & \\
(OECD) Countries & & 9.00 & 83 \\
\hline Italia & 2700.43 & 10.90 & 79 \\
Japan & 3732.56 & 16.84 & \\
USA & 9535.95 & & \\
\hline
\end{tabular}

Source: Authors' elaboration on World Bank Data [47].

However, the analysis carried out shows the national and international intention to improve the level of public health (third SDG). National and international goodwill, therefore, finds fundamental satisfaction in the great and prolific planning of the sector, but the impossibility of reducing the gap between the weak countries and the other ones, as well as reaching a sustainable health system, is evident.

\subsection{The Development Chinese Box}

The research carried out on the three selected countries of the African continent shows that while strategic planning has been developed and applied, operational implementation plans are lacking. In the less-favored areas we studied, the obstacles to achieving the third SDG (i.e., a healthcare system that not only increases average life expectancy but also improves quality in a sustainable way over time) are not attributable to programming, but to the implementation of the programs.

In fact, in the study, various types of long-, medium- and short-term strategic development plans emerged, such as: Governative Plan (G.P), Bilateral Plan (B.P), Intergovernative Plan (I.P) (Figure 2).

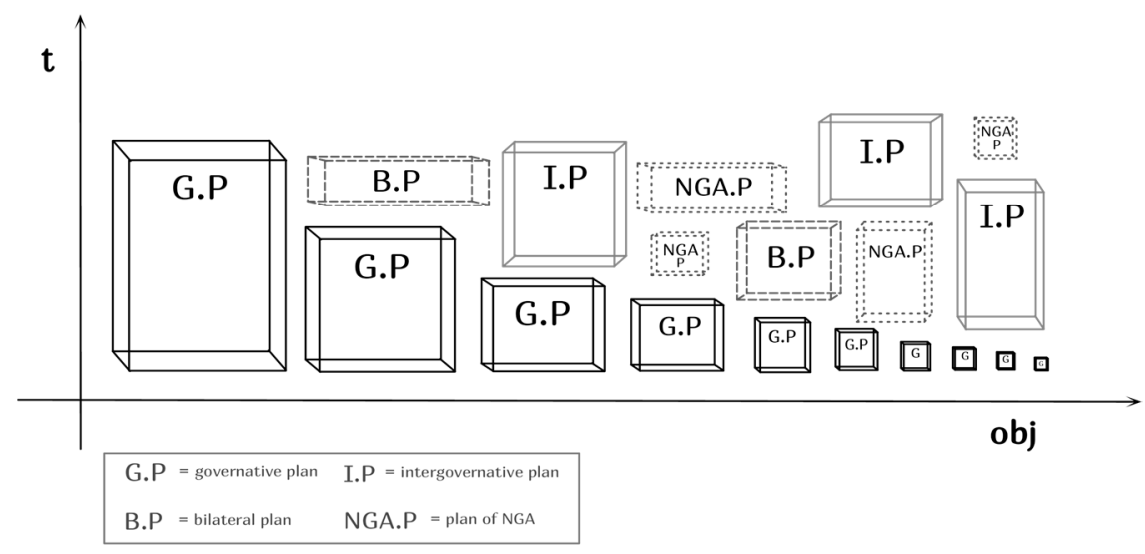

Figure 2. The development Chinese boxes. Source: [9].

In all programs there are the vision, the mission, the strategic analysis, the definition of generic and specific objectives, the strategic indication, but the operational planning and implementation are often postponed to new, more operational plans.

In this way, it is never possible to define the operational implementation of the strategic indication.

This setting creates a system of Chinese boxes that never allows one to get to the implementation of the program, while losing track of the responsibility. In such a complicated system of plans, the NGAs intervene through a para-governmental system replacing the policy-making roles, as theorized 
in the helix model. They implement actions with objectives that are linked to the third SDG, leading the country to the almost involuntary achievement of some development objectives.

One of the main problems is the transition from planning to implementation. All governments have strategic plans and operational plans, but in many cases there are no traces of programs dedicated to implementation, except in specific cooperation plans or actions realized thanks to the international funding. Frequently the implementation of the strategic plan, which is then subdivided into single activities, is appointed to subjects such as civil society, NGOs, volunteers and international projects. Often the strategic plan, although it has been articulated in hundreds of pages, represents more a strategic orientation, more a declaration of intentions than a real long or medium-term work program.

Sometimes, the strategic plan of a government (as in the case of the MTSF in South Africa) becomes a real political manifesto, a program that foresees a term equal to the legislative one and above all presents to the population and international operators a very positive scenario that does not always respond to reality. For this reason, perhaps, it is frequent that the plans do not provide quantitative objectives that can be easily controlled and assessed by the electorate. The other anomaly of many strategic plans analyzed is given by the time period considered, i.e., a medium or short term that is typical of the operational plans. The territory is not a company that can realize its strategic plan in five years: the territory needs time. In transforming or transformable areas, the development path is long; in three years it is difficult to achieve the desired human development. On the other hand, it is also true that territorial strategies are linked to political power and, therefore, generally, to a limited time. These two elements cannot be reconciled with a serious path of human development. Unraveling and redoing the plans, like the canvas of Penelope, many times over the course of time, it is difficult to achieve real and persistent development.

Another element that seems evident when studying the programming of the three countries is that they tend to program for outputs or outcomes: taking example from the UN objectives, i.e., the MDGs first and then the SDGs. This approach highlights that the strategic plan is often a necessity rather than a need. In fact, now all countries, in order to access international funding and skills, must necessarily show the will and structural capacity not only to draft a strategic plan, but also to carry it out. So in some cases, as for Bénin, it is quite clear that the elaboration of the plans is not made exclusively to give a direction to the country, to align with other countries or simply to reach the SDGs, but also to have the possibility to access funding.

In other cases, on the other hand, it is clear that the general intention of the country is mainly to pursue economic development: this emerges by analyzing the budget and more precisely by observing the allocation of resources to the three areas, from which the imbalance of real specific interests derive. In fact, at times, an almost residual portion of investments is attributed to health in total. Often, the bilateral programs, or the plans that link governments to private finance, are more realistic, precise, effective and controllable.

The need to access sources and often also foreign skills, however, does not make development really sustainable, since it becomes impromptu and often dependent. In order to achieve a real sustainable (stable, balanced and long-term) development, the country must be equipped with both strategic and operational plans that may allow it to gradually separate from the international community.

For sustainable health development, it is necessary today that the management of the health system in the less-favored countries provides an integrated double track Top Down and Bottom Up planning and that transforms non-governmental actors from para-state to strategic and operative partners and the international community from institutional decision makers to operational partners.

\subsection{A Helix Systems Model for Sustainable Development of Health}

The health management of a weak area, sometimes clashing with popular beliefs, religions, alternative medicine, should be based on a path of dissemination of good health practices that is specifically designed for that area and that respects its peculiarities. Furthermore, it should consider the possibility of gradually reducing dependence on international, public or private actors. This is 
why the national training of local health personnel becomes strategic, namely doctors, nurses and paramedics. This training should replace that which is provided by foreign operators, thus allowing the independence of the local health system from international conditioning.

In order for a local health system to be able to govern the ordinary health needs of a weak area, as well as the extraordinary needs arising from emergencies (such as epidemics, wars, droughts and other), it is essential that the infrastructures and local professional skills are adequate in relation to the number of inhabitants. This does not always happen and it is for this reason that even ordinary health needs are treated in these areas as emergencies and require significant international interventions in terms of economic, human and professional resources [46].

In order to ensure that the local health system is able to achieve the sustainable development objectives that are formally included in the strategic plans, it is necessary to prepare operational implementation plans that involve the participation of national and international civil society until the government does not become able to manage everything autonomously (as happens in most states with a high human development).

In the implementation phase, in reality, following the results chain of the Organization for Economic Cooperation and Development (OECD)/Development Assistance Committee (DAC) resources-based management (RBM) approach-a management strategy that focuses on the performance and achievement of outputs, outcomes and impact and is composed by resources/input-activities-output-outcomes-impact [48]—and carrying out the planned activities, the general objectives should become impact, the specific outcomes and the output operational objectives. In this way, the programming of a country could be hybridized with a mix of traditional management with project management, the logic framework approach (LFA), the result-based management and the managing for development results MfRD, finding an autonomous and characteristic way to implement strategy through a participative approach based on a bidirectional bottom up and top down system [49]. The application of a participatory method of planning leads to the definition of the logical framework matrix (LFM), also known as project framework matrix [50-52]. MfDR is a management strategy that focuses on the use of performance information to improve decision-making. MfDR involves using practical tools for strategic planning, risk management, progress monitoring, and evaluation of results [53].

More than a health model for weak areas, what is advisable, therefore, is a systems management of a synergy between all the actors of the health development of a country, that is a coordination between spontaneous, para-governmental, independent, international, cooperative and government actions in a single process aimed at the autonomous development of a country's health system. Such a systems management is the core idea of the sustainability helix model, applied to the study of the investigated cases.

The health management process of a weak area that wants to follow the objectives of the UN (SDGs) should be based on a bidirectional approach, both top down and bottom up, i.e., on the possibility to receive from the bottom indications for the solution of health problems through the whole non-governmental system present in the territories and international associations, as well as giving direction from above through the existing strategic plans and meeting the objectives of the international community (SDGs). For example, for vaccination it is already possible to observe, in the studied countries a wide synergy between the various development actors. The government (policy) adopts the international objectives on immunization, the international community (industry) creates projects and devotes funds for immunization, civil society and all non-governmental actors (society) coordinate the implementation of the immunization program through national and international resources. From this example, it clearly appears relevant that all involved actors are ready to play the necessary interface roles also through hybridization processes, as suggested by the Helix models. The logical foundation of the triple helix model is that the effective innovation can only be achieved through the functional integration of three actors [27]. Likewise, the sustainable health development 
of a weak area can only be achieved through the integration of what is identified in the case as the three key actors involved:

1. Sustainable development state (SDS);

2. International community (IC);

3. Non-governmental actors (NGA).

The key hypothesis of the THM incorporated into the sustainability helix model-the interaction between the three actors-is a fundamental process that should trigger a virtuous cycle. Among the other hypotheses previously reported, it is considered that science, hence the knowledge society, plays a central role in innovation processes, hence in finding new possible solutions to problems; then, relationships of virtuous collaborations between the three institutional spheres must be established to ensure an effective 'helix' functioning; finally, most important in the study, the temporary 'replacement' of roles between the three actors through the so-called hybridization processes is often necessary to ensure that each role is played. Well, these are key assumptions also in this study.

The criticisms that the THM has received over time refer essentially to its theoretical abstraction and practical distance from the real world [54-57]. These criticisms are very similar to the criticisms that can be made to the international health planning model. In this work there is an attempt to apply the working process of the model to this specific case.

As shown in Figure 3, where the results of the application of the SHM to this cases study are represented, the helix functioning must be created in particular to direct the implementation process. Accordingly, the expected virtuous dynamic should be directed to favor the realization of the strategy, which is grounded on what policy makers and science have already agreed on (the Health SDG), and it should emerge from the interaction among what are currently identified as key actors: SDS, IC and NDA.

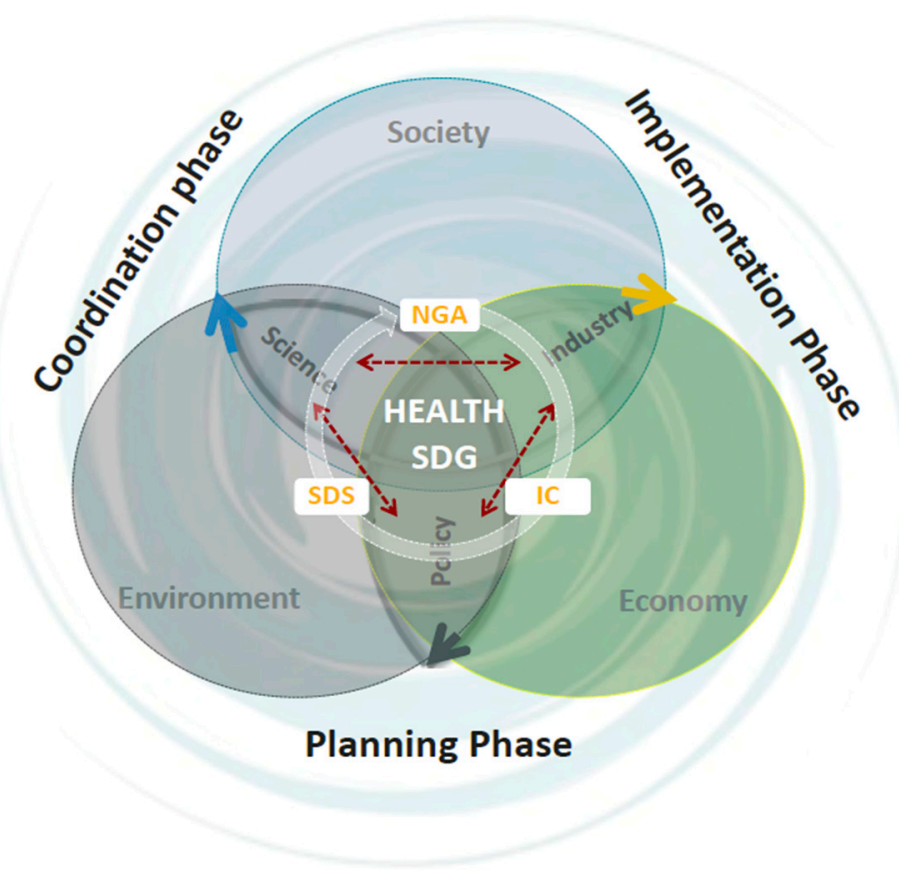

Figure 3. Application of the sustainability helix model to the health Sustainable Development Goal (SDG) governance in the investigated countries (authors' elaboration on [32]).

With respect to the original SHM model, that, regarding the 'context' in which the helix works, suggests the idea of a vortex referring to water [5], this model uses as shown in Figure 3 the idea of wind as the external force which gives a 'field force' to action allowing the real interaction of roles and the effective functioning of the propeller itself: the (health) SDG, i.e., the global objective. 
As the logic of the model suggests, an effective interaction between the three actors is necessary for a correct and wise decision-making process. For example, in order to define appropriate policies for reducing maternal and child mortality:

1. The SDS and the NGA have the task of analyzing the causes of failure in achieving the target index, connoting it within their local context;

2. The international community can be added to the first two actors to give indications on feasible solutions, always considering the local characteristics that emerged during the analysis phase;

3. The NGAs become the cornerstone of the definition of operational plans together with the SDS, becoming an important strategic and implementation tool;

4. The SDS and the NGAs, supported by funding and skills given by the international community (IC), must then devote themselves synergistically to the implementation of the plan and to achieving the objective of reducing maternal and child mortality by enhancing and safeguarding local resources.

With regard to the functioning mechanism of the helix, it remains to be clarified in what conditions the actual interaction occurs. According to the vSa, the effective interaction between actors with different mentalities - as in the case of the three main actors-requires the creation of "consonance" conditions between them, i.e., an alignment based on shared values systems, non-conflicting objectives, effective communication and mutual understanding [7]. Regarding the way to achieve consonance, one should first consider that these conditions cannot be evaluated by analyzing each actor in isolation, nor the way in which the three actors are connected in an organizational structure (that is, statically), as for example, it takes place in a collaborative project. Rather, it is necessary to shift the attention from the actors to the context in which they move, interpreting their behavior as an expression of the influence that their "supra-systems" are able to exert on them. Therefore, to assess the consonance conditions between the three actors, it is necessary to understand their supra-systems contexts. For example, policymakers are very influenced by the political-institutional system that nominated them, by the need to be accredited in the international political environment and the need to access foreign resources and skills. According to the consonance perspective, collaboration is not simply a question of participation in a common project: it requires an effective sharing of information and communications to achieve common objectives.

Therefore, the key to the model is that the actors should mutually conform to each of the planned roles (and also to any substitutions or integrations) in order to achieve a virtuous helix dynamic, i.e., a set of individual actions effectively integrated to pursue shared goals. Such synergetic results, however, are not totally secure, given that these institutional actors generally tend to pursue their own interests.

The above concept of hybridization that can be seen as a key factor in THM is particularly interesting and fundamental in the SHM integrated model for several reasons [33]:

1. First, because it emphasizes that, to achieve the expected results (e.g., reduction of deaths from AIDS, etc.), there are roles that must be interpreted by any actor, even if they are not institutionalized as such; for example, NGOs can be called to play a para-governmental role.

2. Secondly, because it promotes an exchange of roles that is particularly useful for considering the different perspectives; fundamental to making the local community understand local peculiarities (for example, concerning the alternative medicine of healers).

3. Third, because it introduces the definition of possible "interface" roles that may be fundamental to effectively interconnecting the three key actors, especially when they are institutionally incapable or ineffective at playing a specific role that is important for producing the helix dynamics.

Therefore, developing the concept of an "interface", based on that of hybridization, you can find a fundamental element to favor and support an effective interaction. Specifically, as shown in these cases, the notion of interface can help to identify possible "vacancies" at any level of the plan that must 
be covered. Of course, these roles, over time, can be institutionalized or modified, or removed, when this becomes structurally necessary for the process.

The proposed model and in particular the developed notion of interface role are the bases on which the institutional approach to healthcare management is further discussed in the following phases.

The complex system of interactions that emerges from the global relational context represented through the vSa sustainability helix model can determine a more or less balanced equilibrium in which the dominant values and the priorities at stake are reflected through the roles interpreted by the three actors. The role of individual development actors (the international community, the sustainable development state and non-governmental actors) should change in relation to the phase that they are going through. The solutions could, however, emerge from the intersection of the points of view of the three main actors, in which each of them can represent a significant interface role, not only fulfilling their institutional functions, but also favoring the hybridization processes.

In the proposed model, the SDS, IC and NGAs are highly representative actors of the three dimensions of sustainability and for this reason they should be responsible for its achievement in the territory. Four phases could represent the fundamental steps for the achievement of the sub-objectives of the third SDG, i.e., the identification of problems, the identification of solutions, the operational planning, and the implementation of local health systems. Governments, and in particular the SDS, must be the key interface with all the interlocutors of the system. The main responsibility is to correctly interpret environmental needs and establish the set of constraints, rules, and incentives necessary to regulate the lives of populations and to ensure long-term sustainability. The SDS must maintain the governance of the local health system's development, must guarantee the entire population, and create, an efficient and effective healthcare system for everybody. However, they can officially involve the other actors operating in the territory, thus accessing skills and information that they do not possess independently.

The IC has dominated for a long time, and in many cases still dominates, the health development of some weak territorial areas, sometimes putting at the center international interests at the expense of local ones. Although it has been and is able to provide a short-term satisfaction of the health needs of weak countries, sometimes this comes at the expense of a vision of global sustainability, which has to do with both the social sphere and environmental sustainability. The IC should not, therefore, deal with all phases autonomously, as often happens, but insert itself, for example, as operational support for the resolution of problems and the implementation of operational plans established by the territories.

NGAs often succeed in quickly identifying the real problems of the territories, since they act on the field. In the same way, they are able to identify the really applicable solutions and the way to apply them and achieve the expected results. Moreover, like the IC, they often also have the skills to implement operational plans. Like the SHM suggests, NGAs can play a fundamental interface role among all actors, unifying points of view and sustainability challenges, thus creating the 'field force' necessary for general engagement and commitment to sustainable health.

As for sustainability in general [24], also in this case harmonizing independent actions is still far off. Almost all the identified actors tend to express their interests and to realize them independently. In cases of integrated plans between several actors (such as bilateral plans), you can find laudable objectives, but often these are transformed into systems to access the resources of the other actors, far from a real scheme of co-operation and co-creation of value.

The goal, therefore, should be to achieve a harmonious movement of the propeller necessary for the achievement of the SDGs, triggering a virtuous interaction between the three main actors (SDS, IC, NGA), which is essential to create the necessary conditions for sustainable health development.

\section{Conclusions}

This study is the outcome of a reflection inspired by the theme "sustainability for healthcare" that suggests exploring fruitful connections between the two fields both at theoretical and practical level. 
Accordingly, the study looks at healthcare as one of the fundamental SDGs, indeed the third one, that all nations are called to achieve by 2030 .

Focusing the attention on countries that are less favored in the achievement of development, the work investigates the reasons why achieving the SDGs, with particular reference to health, is particularly difficult in these countries. Of course, these countries suffer from the scarcity of resources far more than developed ones. However, the focus is not on this problem. As emerges from the empirical analysis of facts in the three African countries analyzed, there is indeed a huge effort in planning for health in these areas that involve many actors. However, data do not provide evidence of success of this planning effort.

Recognizing the interconnections between the global and local approach to development, and framing the health SDG achievement in weak countries as a global development issue allow us to recover unitary features and coherence in the action at global and local level, which is necessary especially in the case of health in a globalized world.

The enlargement of the development view from the local to the global level is then supported by the search of a different perspective, useful for providing a framework in which focus is on actors and roles played in the governance of development, hence of healthcare. Going beyond the domain of economic development that the literature review indicated as the main reference in the study of development, there are useful references in the field of managerial studies where the focus is on the governance and management approaches of organizations, not only business ones. With the interpretative support of the sustainability helix model, in particular, it is possible to identify important aspects that provide insights not only for understanding the limited implementation success of healthcare planning in the investigated countries but also to identify possible solution pathways.

The derived sustainable health development system model shows, in particular, key planning and implementation roles to be played by key actors and, what is most important, the necessity of a systemic, hence harmonic interaction among them represented through the 'helix' functioning, obtained also through hybridization processes of roles.

In conclusion, planning could remain a sterile hierarchical process, more than often affected by personal interests, if a strong commitment to the achievement of a shared goal is lacking. Only a systemic engagement of actors towards the achievement of the planned goal, based not so much on complying with assigned institutional roles and responsibilities but on practical sharing of values and views, can help realize the planned (health) development.

In this respect, the value of this study is in the effort to provide a comprehensive view of the investigated problem highlighting the contribution of the sustainable development global perspective to frame problems like healthcare in less-favored areas that are local but require global engagement.

Probably, on the other hand, the same wide view proposed could give rise to critiques that highlight the limitations of the study. For example, the use of the triple helix model in the context of developing countries has been criticized [58]. The revised version of the model that has been used in this work, however, recognizes, hence valorizes, the inner systemic functioning of the helix to which the general validity appears linked, instead of more specific interpretations of the model.

Certainly, the study does not remain immune to limitations both at theoretical and practical level. However, the ultimate purpose is to stimulate reflection and debate on the need of general frameworks of reference when dealing with relevant issues like health and poverty. The sustainability and sustainable development frameworks appear generally important references that should be always considered, both at theoretical and practical level, in the analysis of any kind of societal, economic as well as environmental issue [59-63]. Future research is required in this context to link local and specific models of action to the general frameworks of sustainability and sustainable development in order to consider as universal paradigm of reference. 
Author Contributions: Conceptualization, M.S. and F.S.; methodology, M.S., F.S. and A.R.; validation, F.S., A.R. and G.G.A.; formal analysis, F.S. and A.R.; investigation, F.S., A.R. and G.G.A.; resources, F.S., A.R. and G.G.A.; data curation, F.S., A.R. and G.G.A.; writing—original draft preparation, M.S., F.S. and A.R.; writing-review and editing, M.S., F.S. and A.R.; visualization, A.R. and G.G.A.; supervision, M.S. and F.S.

Funding: This research received no external funding.

Conflicts of Interest: The authors declare no conflict of interest.

\section{References}

1. Sustainable Development. Available online: https://sustainabledevelopment.un.org/sdgs (accessed on 30 December 2018).

2. UN Sustainable Development Goals. Available online: https://www.un.org/sustainabledevelopment/ health/ (accessed on 30 December 2018).

3. Barile, S. Management Sistemico Vitale. Decidere in Contesti Complessi; Giappichelli: Torino, Italy, 2009.

4. Barile, S. Contributions to Theoretical and Practical Advances in Management. A Viable Systems Approach (vSA); Aracne: Roma, Italy, 2013.

5. Golinelli, G.M.; Barile, S.; Saviano, M.; Farioli, F.; Masaru, Y. Towards a common framework for knowledge co-creation: Opportunities of collaboration between Service Science and Sustainability Science. In Service Dominant Logic, Network and Systems Theory and Service Science: Integrating Three Perspectives for a New Service Agenda; Gummesson, E., Mele, C., Polese, F., Eds.; Giannini: Napoli, Italy, 2015.

6. Barile, S.; Pels, J.; Polese, F.; Saviano, M. An introduction to the viable systems approach and its contribution to marketing. J. Bus. Mark. Manag. 2012, 5, 54-78.

7. Barile, S.; Saviano, M. Foundations of systems thinking: The structure-system paradigm. In Contributions to Theoretical and Practical Advances in Management. A Viable Systems Approach (VSA); Various Authors; International Printing: Avellino, Italy, 2011; pp. 1-24.

8. Sciarelli, F.; Rinaldi, A. Il Macro-Management per le Aree Deboli del Mondo; Franco Angeli: Milano, Italy, 2018.

9. Sciarelli, F.; Rinaldi, A. Development Management of Transforming Economies. Theories, Approaches and Models for Overall Development; Palgrave Macmillan: London, UK, 2017; pp. 139-158.

10. Etzkowitz, H. The triple helix as a model for innovation studies. Sci. Publ. Pol. 1998, 25, 195-203.

11. Elkington, J. Cannibals with Forks. The Triple Bottom Line of 21st Century; New Society Publishers: London, UK, 1997.

12. Rostow, W.W. The Stages of Economic Growth: A Non-Communist Manifesto; Cambridge University Press: Cambridge, UK, 1960; pp. 4-16.

13. Lewis, W.A. Economic Development with Unlimited Supplies of Labour. Manch. Sch. 1954, 22, $139-191$. [CrossRef]

14. De la Croix, D.; Docquier, F. Do brain drain and poverty result from coordination failures? J. Econ. Growth 2012, 17, 1-26. [CrossRef]

15. Deaton, A. Understanding the Mechanisms of Economic Development. J. Econ. Perspect. 2010, $24,3-16$. [CrossRef]

16. Rinaldi, A.; Sciarelli, F. Overall Development Management Model: A New Approach for Emerging Countries. Comparative Analysis of Six Countries on Two Continents. J. Syst. Cybern. Inform. 2017, 15, 7.

17. Rinaldi, A.; Sciarelli, F. Economic and Social Causes for a Late Development: India vs. Ethiopia. Int. J. Econ. Policy Emerg. Econ. 2018, 11, 83-99.

18. Dixon, D.F. Macromarketing: A social systems perspective. J. Macromarket. 1984, 4, 4-17. [CrossRef]

19. Gummesson, E. Practical Value of Adequate Marketing Management Theory. Eur. J. Market. 2002, 36, 325-349. [CrossRef]

20. Ritter, T.; Wilkinson, I.F.; Johnston, W.J. Managing in complex business networks. Ind. Market. Manag. 2014, 33, 175-183. [CrossRef]

21. Mushkin, S.J. Health as an Investment. J. Polit. Econ. 1962, 70, 129-157. [CrossRef]

22. Thomas, D.; Frankenberg, E. Health, Nutrition and Prosperity: A Microeconomic Perspective. Bull. World Health Organ. 2002, 80, 106-113. [PubMed]

23. Deaton, A. Health, Inequality and Economic Development. J. Econ. Lit. 2003, 41, 113-158. [CrossRef] 
24. Hansmann, R.; Mieg, H.A.; Frischknecht, P. Principal sustainability components: Empirical analysis of synergies between the three pillars of sustainability. Int. J. Sustain. Dev. World Econ. 2012, 19, 451-459. [CrossRef]

25. Barile, S.; Saviano, M.; Iandolo, F.; Calabrese, M. The Viable Systems Approach and its Contribution to the Analysis of Sustainable Business Behaviors. Syst. Res. Behav. Sci. 2014, 31, 683-695. [CrossRef]

26. Barile, S.; Saviano, M.; Iandolo, F.; Caputo, F. La dinamica della sostenibilità tra vortici e correnti: Un modello a Tripla Elica. In Sviluppo, Sostenibilità e Competitività delle Aziende. Il Contributo degli Economisti Aziendali; Borgonovi, E., Aiello, G., Fellegara, A.M., Eds.; Il Mulino: Bologna, Italy, 2017; pp. 61-82.

27. Etzkowitz, E.; Leydesdorff, L.A. Universities and the Global Knowledge Economy: A Triple Helix of Universityindustry-government Relations; Cassell: London, UK, 1997.

28. Dzisah, J.; Etzkowitz, H. Triple helix circulation: The heart of innovation and development. Int. J. Technol. Man. Sustain. Dev. 2008, 7, 101-115. [CrossRef]

29. Barile, S.; Saviano, M. Complexity and Sustainability in Management: Insights from A Systems Perspective. In Social Dynamics in a Systems Perspective; Barile, S., Pellicano, M., Polese, F., Eds.; Springer International Publishing: New York, NY, USA, 2018; pp. 39-63.

30. Farioli, F.; Barile, S.; Saviano, M.; Iandolo, F. Re-reading sustainability through the Triple Helix model in the frame of a systems perspective. In The Sage Handbook of Nature; Marsden, T., Ed.; SAGE: London, UK, 2018; pp. 10-37.

31. Scalia, M.; Barile, S.; Saviano, M.; Farioli, F. Governance for Sustainability: A Triple Helix Model. Sustain. Sci. 2018, 13, 1235-1244. [CrossRef]

32. Saviano, M.; Barile, S.; Farioli, F.; Orecchini, F. Strengthening the science-policy-industry interface for progressing toward sustainability: A Systems thinking view. Sustain. Sci. 2019. forthcoming.

33. Carayannis, E.G.; Barth, T.D.; Campbell, D.F. The Quintuple Helix innovation model: Global warming as a challenge and driver for innovation. J. Innov. Entrep. 2012, 1, 2. [CrossRef]

34. Pender, J.; Hazel, P. Promoting Sustainable Development in Less-Favored Areas; International Food Policy Research Institute: Washington, DC, USA, 2000.

35. Todaro, M.P. A Model of Labor Migration and Urban Unemployment in Less Developed Countries. Am. Econ. Rev. 1969, 59, 138-148.

36. Stark, O.; Bloom, D. The New Economics of Labor Migration. Am. Econ. Rev. 1985, 75, 173-178.

37. Taylor, J.; Arango, J.; Hugo, G.; Kouaouci, A.; Massey, D.; Pellegrino, A. International Migration and Community Development. Int. Migr. Community Dev. 1996, 62, 397-418. [CrossRef]

38. Nyberg-Sorensen, N.; Van Hear, N.; Engberg-Pedersen, P. The Migration-Development Nexus: Evidence and Policy Options. Int. Migr. 2002, 40, 49-73. [CrossRef]

39. National Development Plan. Available online: www.gov.za/issues/national-development-plan-2030 (accessed on 30 December 2018).

40. National Health Insurance. Available online: www.gov.za/documents/national-health-act-national-healthinsurance-policy-towards-universal-health-coverage-30 (accessed on 30 December 2018).

41. Medium Term Strategic Framework. Available online: www.gov.za/documents/medium-term-strategicframework-2014-2019 (accessed on 30 December 2018).

42. Budget Review 2015. Available online: www.treasury.gov.za/documents/national\%20budget/2015/review/ chapter\%205.pdf (accessed on 30 December 2018).

43. Health Financing System. Available online: https://openknowledge.worldbank.org/bitstream/handle/ 10986/24119/9781464808159.pdf;sequence=2 (accessed on 30 December 2018).

44. Health Sector Development Program IV. Available online: https://phe-ethiopia.org/admin/uploads/ attachment-721-HSDP\%20IV\%20Final\%20Draft\%2011Octoberr\%202010.pdf (accessed on 30 December 2018).

45. Growth and Transformation Plan II (GTP II). Available online: https://www.cmpethiopia.org/media/gtp_ ii_policy_matrix_english_final_august_2016_2 (accessed on 30 December 2018).

46. National Health Development Plan. Available online: http://www.nationalplanningcycles.org/sites/ default/files/country_docs/Benin/benin_pnds_definitif_mis_en_forme_revue_le_21_juillet_2010_-_en. pdf (accessed on 30 December 2018).

47. Available online: data.worldbank.org (accessed on 25 February 2019).

48. ISTAT Sanità e Salute. Available online: https://www4.istat.it/it/files/2017/12/C04.pdf (accessed on 30 December 2018). 
49. Alesani, D. Result based management. In Management of International Institutions and NGOs; Missoni, E., Alesani, D., Eds.; Routledge: London, UK, 2014; p. 78 et seq.

50. Cleland, D.I. Project Management: Strategic Design and Implementation; McGraw-Hill: New York, NY, USA, 2007.

51. Bussi, F. Progettare in Partenariato; Franco Angeli: Milano, Italy, 2001.

52. Rossi, M. I progetti di Sviluppo; Franco Angeli: Milano, Italy, 2004.

53. Stroppiana, A. Progettare in Contesti Difficili; Franco Angeli: Milano, Italy, 2009.

54. Managing for Development Results. Available online: http://www.oecd.org/dac/effectiveness/41178251. pdf (accessed on 30 December 2018).

55. Cooke, P. Regional asymmetric knowledge capabilities \& open innovation. Exploring 'globalisation 2': A new model of industry organisation. Res. Pol. 2005, 34, 1128-1149.

56. Brännback, M.; Carsrud, A.; Krueger, N.; Elfving, J. Challenging the triple helix model of regional innovation systems: A venture-centric model. Int. J. Technoentrepreneurship 2008, 1, 257-277. [CrossRef]

57. Viale, R.; Pozzali, A. Complex adaptive systems and the evolutionary triple helix. Crit. Soc. 2010, 36, 575-594. [CrossRef]

58. Amir, S.; Nugroho, Y. Beyond the Triple Helix: Framing STS in the Developmental Context. Bull. Sci. Technol. Soc. 2013, 33, 115-126. [CrossRef]

59. Aquino, R.P.; Barile, S.; Grasso, A.; Saviano, M. Envisioning smart and sustainable healthcare: 3D Printing technologies for personalized medication. Futures 2018, 103, 35-50. [CrossRef]

60. Scalia, M.; Angelini, A.; Farioli, F.; Mattioli, G.F.; Saviano, M. The chariots of Pharaoh at the red sea: The crises of capitalism and environment. A modest proposal towards sustainability. Cult. Della Sosten. 2016, 1, 3-63.

61. Saviano, M.; Barile, S.; Spohrer, J.C.; Caputo, F. A service research contribution to the global challenge of sustainability. J. Serv. Theory Pract. 2017, 27, 951-976. [CrossRef]

62. Saviano, M.; Di Nauta, P.; Montella, M.M.; \& Sciarelli, F. The Cultural Value of Protected Areas as Models of Sustainable Development. Sustainability 2018, 10, 1567. [CrossRef]

63. Aquino, R.; Barile, S.; Grasso, A.; Saviano, M. Managing variety in healthcare through personalized medication: The contribution of 3D-printing technologies. In Cybernetics and Systems. Social and Business Decisions; Barile, S., Espejo, R., Perko, I., Saviano, M., Eds.; Systems Management Book Series; Giappichelli-Routledge: Abingdon, UK, 2019; pp. 345-350.

(C) 2019 by the authors. Licensee MDPI, Basel, Switzerland. This article is an open access article distributed under the terms and conditions of the Creative Commons Attribution (CC BY) license (http:/ / creativecommons.org/licenses/by/4.0/). 